\title{
OBJECT-BASED SYMMETRIC DIFFERENCE FOR LAND SURFACE SEGMENTATION SCALE PARAMETER OPTIMISATION
}

\author{
G. J. Louw ${ }^{\text {a }}$, A. Van Niekerk ${ }^{\mathrm{a}, \mathrm{c}}$, A. Rozanov ${ }^{\mathrm{b}}$ \\ ${ }^{\text {a }}$ Dept. of Geography and Environmental Science, Stellenbosch University - gerritlouw @ gmail.com, avn@sun.ac.za \\ ${ }^{\mathrm{b}}$ Dept. of Soil Science, Stellenbosch University - dar@sun.ac.za \\ ${ }^{c}$ School of Plant Biology, University of Western Australia, 35 Stirling Hwy, Crawley WA 6009, Perth, Australia
}

\begin{abstract}
KEY WORDS: GEOBIA, Geomorphometry, Land surface segmentation, Scale parameter optimisation
\end{abstract}
\begin{abstract}
Although multi-resolution segmentation (MRS) has been shown to delimit geomorphological boundaries more accurately than other available segmentation procedures, the selection of the appropriate parameters remains a challenge. The optimisation of scale has largely been focussed on deriving suitable scale parameters (SPs). Local variance (LV) has been shown to exploit spatial autocorrelation for identifying suitable SPs. However, further investigation into SP selection for land surface segmentation is necessary. This paper demonstrates how symmetric difference (SD) can be used to detect suitable SPs when segmenting continuous land surfaces. Comparisons with an established suitable SP selection technique (ESP 2) are made and, finally, it is concluded that SD provides a simple and effective way of selecting suitable SPs for land surface segmentation.
\end{abstract}

\section{INTRODUCTION}

The creation of fine scale geomorphological maps often involves the segmentation of continuous land surfaces into landform elements or landform components (Drăguţ and Eisank, 2011). Even though the pixel-based delimitation of landform components are well established (Evans, 2012), the segmentation of continuous terrain through object-orientated segmentation has received much attention in recently published literature (Drăguţ and Blaschke, 2008; Eisank et al., 2014, 2011; Van Niekerk, 2010). This can, at least partly, be ascribed to the presence of the salt-and-pepper effect in pixel-based approaches, which compromises landform component homogeneity (Blaschke, 2010; Gao et al., 2011).

To evaluate which segmentation algorithm consistently generates morphologically representative landform components, Van Niekerk (2010) evaluated three object-based segmentation algorithms - automated land component mapper (ALCoM), iterative self-organizing data analysis technique algorithm (ISODATA) and multi-resolution image segmentation (MRS) of which the MRS algorithm, implemented in eCognition (Trimble), performed the best.

MRS is a region-merging algorithm that creates homogenous objects based on a user defined scale parameter (SP) (Baatz and Schäpe, 2000). As the SP is primarily used to control the average size of the objects, it is the chief parameter through which the analyst can manipulate the output of MRS when segmenting continuous land surfaces (Drăguţ et al., 2011).

Drăguţ et al (2009) investigated the use of local variance (LV) to evaluate the relationship between object homogeneity and SP. This ultimately led to the development of the estimation of scale parameter (ESP) tool in eCognition (Drăguţ et al., 2010). The tool was later modified to allow for multi-layered approaches to SP optimisation, resulting in ESP 2 (Drăguţ et al., 2014).

LV-based SP selection is fundamentally based on the consideration of the indirect relationship between SP and object topology. As the SP is systematically increased, the object size will increase, and consequently object boundaries are affected. This, in turn, defines the interior object homogeneity and thus LV.

While LV-based SP selection has been shown to aid the delimitation of geomorphological features (Drăguţ et al., 2011), there is still a need for a topological investigation of the relationship between SP and object boundaries.

Accordingly, this study aims to evaluate the use of SD as a method for identifying suitable SPs in multi-resolution land surface segmentation. The authors demonstrate how SD can be used to identify suitable SPs using slope gradient as input to MRS, and conclusions are drawn within the context of finding a simple and effective technique for identifying SPs for objectbased geomorphometry applications.

\section{MATERIALS AND METHODS}

\subsection{Study Area}

A $420 \mathrm{~km}^{2}$ study area was chosen within the Letaba water catchment area (Limpopo province, South Africa), located in the Lowveld geomorphic province (Figure 1). Dominant tertiary sediments (manifested as river terraces) and planation surfaces occur throughout, whilst intermittently interrupted by inselbergs (Venter and Bristow, 1986).

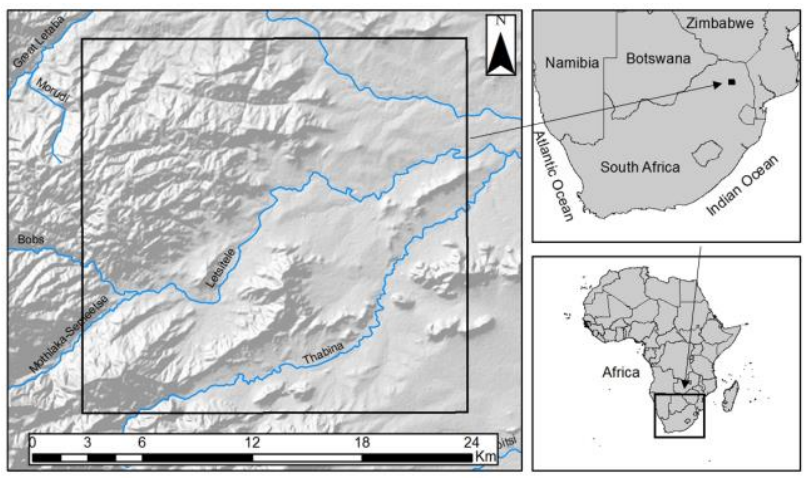

Figure 1 Map of the study area located in Limpopo, South Africa 


\subsection{DEM}

Fine scale land surface segmentation requires high resolution digital elevation models (DEMs). For this reason, level 2 of the $5 \mathrm{~m}$ Stellenbosch University DEM (SUDEM) was used. To construct the SUDEM, a combination of interpolators was used to create a continuous surface of elevation from both large scale contour and spot data. Finally, areas with low density contour and spot heights were supplemented with the $30 \mathrm{~m}$ void-filled SRTM (Van Niekerk, 2015).

\subsection{LSPs}

Since a multi-level segmentation is not necessary for illustrating SD-based SP selection, and in favour of simplicity, the only LSP chosen for the study was slope gradient. Using ArcGIS, a 10.3 slope gradient was calculated with a $3 \times 3$ kernel and the maximum averaging technique (ESRI, 2016).

\subsection{MRS Parameters}

MRS has three parameters to optimise for accurate land surface segmentation: shape, compactness and SP. First, shape and compactness were both set to zero as this permits the segmentation to only consider colour when merging pixels. SP, on the other hand, was iterated for every value between one and 100 .

\subsection{SP Optimisation Techniques}

\subsubsection{ESP 2}

ESP 2, an unsupervised SP optimisation technique, calculates $\mathrm{LV}$ at different SP intervals to estimate when objects approximate real-world features. Breaks in the LV graph are investigated to identify optimal SPs. However, the semivariogram-like LV trend shows too little variation to facilitate accurate optimal SP selection. Consequently, Drăguţ et al (2010) suggested the use of rate of change (ROC) (Bauer and Dahlquist, 1999) to evaluate the subtleties in LV from one SP to the next. In addition to LV-ROC, a non-linear cubic regression approach (with a very high $\mathrm{R}^{2}$ ) was also implemented to isolate LV residuals and to facilitate selection of LV peaks.

\subsubsection{SD}

The SD between object boundaries - derived from neighbouring SPs - is calculated to identify SPs where landform components are suitably delimited. As SP is systematically increased, the resultant objects' sizes will also increase until such a point where the objects match the real-world landform components. At this point, small systematic increases in SP will have little effect on SD. When SP is sufficiently increased, SD will show a distinct peak as mayor changes in object boundaries occur when the objects conform to a new landscape organisational level.

To calculate SD, SP is iterated for every value between one and 100. Each object set, derived from each SP, is then converted to polygons. The polygons are then exported as lines in the form of a shapefile. Lastly, the SD is calculated (using ArcGIS 10.3.1) between neighbouring SPs and the total SD distance is calculated in metres. Consequently, the length of the remaining object boundaries (SD) is quantified and can be visualised graphically for interpretation purposes.

\section{RESULTS}

The selection of optimal SPs from ESP 2 and SD necessitated visual inspection of both graph and map outputs. Only SPs between 1 and thirty were considered, as larger SPs resulted in non-geomorphologically representative objects.

\subsection{ESP 2}

Visual interpretations of peaks in LV-ROC resulted in seven suitable SPs (10, 13, 15, 18, 21, 23 and 30) being identified. Only five of these SPs corresponded with the ten SPs $(8,10,11$, $13,15,19,21,24,25$ and 30) obtained from peaks and knickpoints in the $\mathrm{LV}$ cubic regression $\left(\mathrm{R}^{2}=1, \mathrm{p}<0.0001\right)$ residuals graph (Figure 2). The process of selecting suitable SPs from the LV and LV-ROC graphs has been automated by Drăguţ et al (2014), but the SP as suggested by ESP 2 was 100, which resulted in objects that were too large to represent the geomorphology of the area.

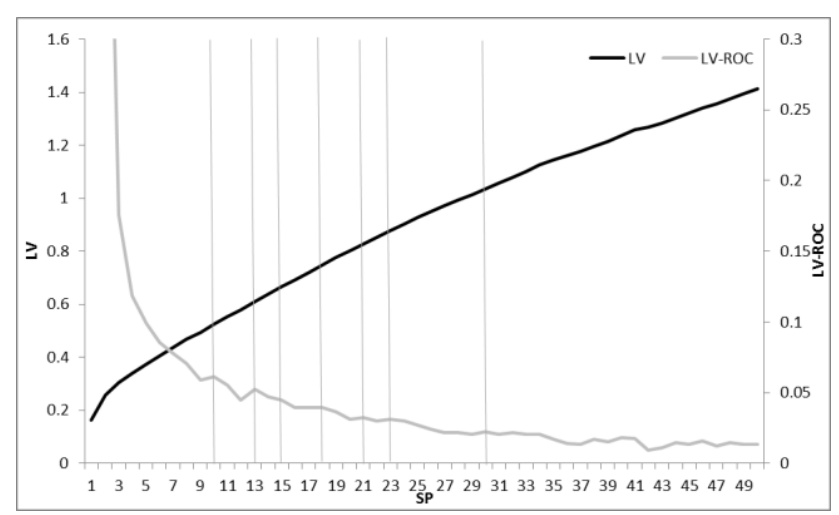

Figure $2 \mathrm{LV}$ and LV-ROC graphed across SP; derived using ESP 2. The grey vertical lines represent the position of suitable SPs based on LV-ROC peaks.

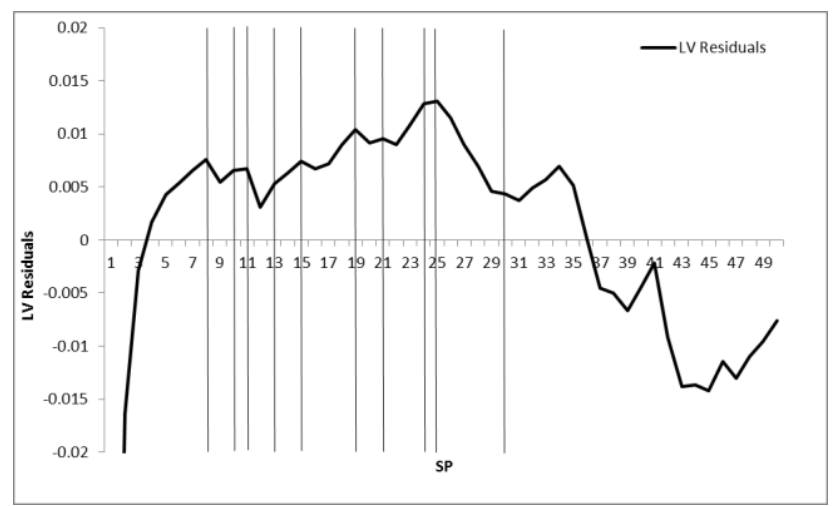

Figure $3 \mathrm{LV}$ cubic regression residuals $\left(\mathrm{R}^{2}=1, \mathrm{p}<0.0001\right)$. The black vertical lines represent the position of suitable SPs based on either knick-points or peaks.

\subsection{SD}

Four peaks, located at SP values 10, 12, 15 and 25 are clearly visible in the SD results (Figure 4). These peaks represent dramatic increases in SD as a result of the delayed responses in object boundary changes, ascribed to the systematic increase in SP. 


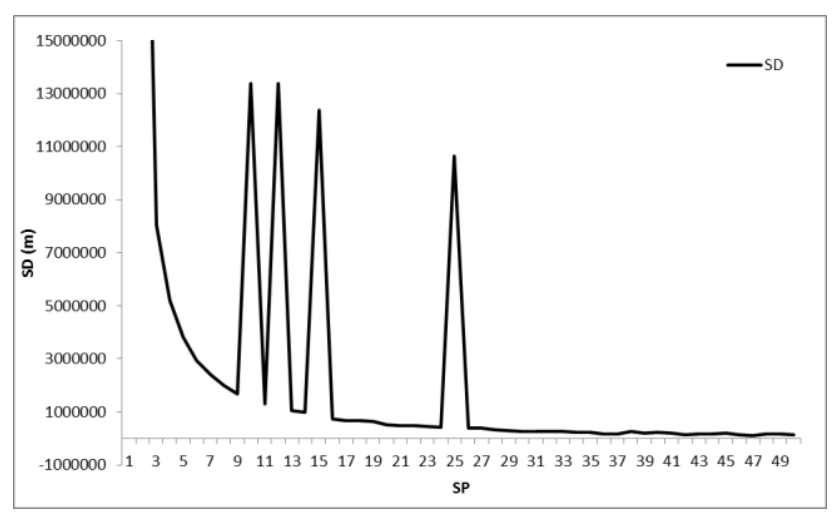

Figure 4 SD graphed across SP, showing four dramatic peaks indicative of large changes in object boundaries and, consequently, the position of suitable SPs.

Figure 5 maps the SD of SPs 8 to 12 for the study site. The four large peaks (dramatic increases in SD) in Figure 4 are clearly noticeable in Figures $8 \mathrm{~b}$ and $8 \mathrm{~d}$, while the remaining Figures $8 \mathrm{a}$ and $8 \mathrm{c}$ show comparatively fewer changes in object geometry.

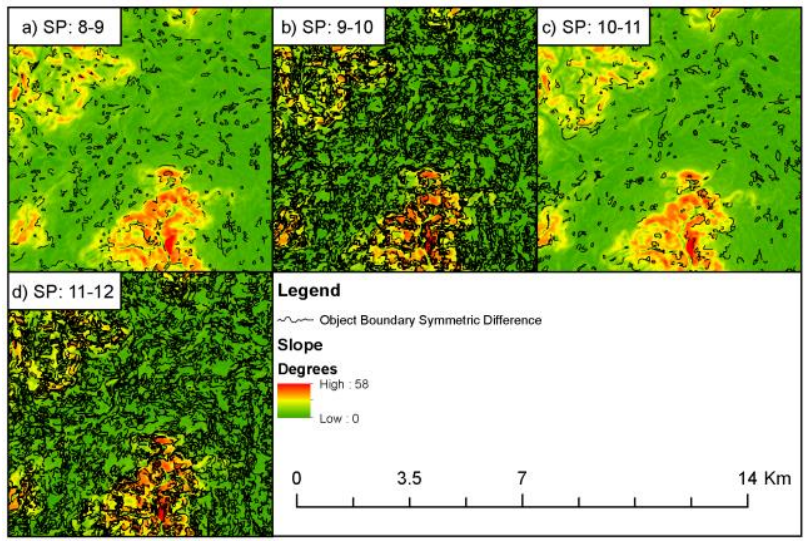

Figure 5 Spatial visualisation of SD across the study area, calculated as the difference of the object boundaries between neighbouring SPs 8 and 9, 9 and 10,10 and 11 , and finally, 11 and 12 .

\section{DISCUSSION AND CONCLUSION}

The homogeneity criterion, controlled by SP, serves as a common denominator between the LV and SD, and defines the causal relationship between object homogeneity and object topology. This relationship is further evident from the fact that three of the four SD selected SPs also registered in the LV response from object homogeneity.

The only SD-based selected SP not selected by ESP 2 was 12 , however, an unmistakable drop in LV at this particular position indicates that large changes in object topology between neighbouring SPs can result in either a peak or drop in LV. These results support observations by Gerçek et al. (2011) that drops in LV-ROC can also be indicative of suitable SPs.

We conclude that suitable SP selection using LV-ROC and regression residual graphs remains challenging as vital interpretations are not only subjective to analysts' interpretations, but are also greatly affected by the large number of possible suitable SPs represented as both peaks and drops in LV. In contrast, SD graphs are much easier to interpret and provide the added advantage that it can be visualised spatially (as demonstrated in Figure 5). SD clearly shows promise for guiding SP selection for geomorphometry applications, but more work is required to automate the process and to evaluate it in different areas and on different source DEMs.

\section{ACKNOWLEDGEMENTS}

This research is financially supported by the National Research Foundation (NRF). Additionally, the Centre of Geographical Analysis (CGA) from Stellenbosch University (SU) is thanked for suppling the $5 \mathrm{~m}$ SUDEM.

\section{REFERENCES}

Baatz, M., Schäpe, A., 2000. Multiresolution segmentation - An optimization approach for high quality multi-scale image segmentation. Angew. Geogr. Informationsverarbeitung XII 12-23. doi:Export Date 6 May 2013

Bauer, R.J., Dahlquist, J.R., 1999. Technical market indicators: Analysis \& performance. Wiley, New York.

Blaschke, T., 2010. Object based image analysis for remote sensing . ISPRS J. Photogramm. Remote Sens. 65, 2-16.

Drăguţ, L., Blaschke, T., 2008. Terrain segmentation and classification using SRTM data. Adv. Digit. terrain Anal. 141-158. doi:10.1007/978-3-540-77800-4_8

Drăguţ, L., Csillik, O., Eisank, C., Tiede, D., 2014. Automated parameterisation for multi-scale image segmentation on multiple layers. ISPRS J. Photogramm. Remote Sens. 88, 119-127. doi:10.1016/j.isprsjprs.2013.11.018

Drăguţ, L., Eisank, C., 2011. Object representations at multiple scales from digital elevation models. Geomorphology (Amst). 129, doi:10.1016/j.geomorph.2011.03.003

183-189.

Drăguț, L., Eisank, C., Strasser, T., 2011. Local variance for multi-scale analysis in geomorphometry. Geomorphology 130, 162-172. doi:10.1016/j.geomorph.2011.03.011

Drăguţ, L., Eisank, C., Strasser, T., Blaschke, T., 2009. A comparison of methods to incorporate scale in Geomorphometry. Proc. Geomorphometry 2009. Zurich, Switzerland, 31 August - 2 Sept. 2009 133-139.

Drăguţ, L., Tiede, D., Levick, S.R., 2010. ESP: a tool to estimate scale parameter for multiresolution image segmentation of remotely sensed data. Int. J. Geogr. Inf. Sci. 24, 859-871. doi:10.1080/13658810903174803

Eisank, C., Drăguț, L.D., Blaschke, T., 2011. A generic procedure for semantics-oriented landform classification using object-based image analysis. Geomorphometry 2011, 8 Sept. 2011, Redlands, USA 125-128.

Eisank, C., Smith, M., Hillier, J., 2014. Assessment of multiresolution segmentation for delimiting drumlins in digital elevation models. Geomorphology 214, 452-464. doi:10.1016/j.geomorph.2014.02.028

ESRI, 2016. ArcGIS - The Complete Geographic Information System [online] [WWW Document] URL http://www.esri.com/software/arcgis/index.html (accessed 6.2.16).

Evans, I.S., 2012. Geomorphometry and landform mapping: What is a landform? Geomorphology 137, 94-106. doi:10.1016/j.geomorph.2010.09.029

Gao, Y., Mas, J.F., Kerle, N., Navarrete Pacheco, J.A., 2011. Optimal region growing segmentation and its effect on classification accuracy. Int. J. Remote Sens. 32, 37473763. doi:10.1080/01431161003777189

Gerçek, D., Toprak, V., Strobl, J., 2011. Object-based classification of landforms based on their local geometry and geomorphometric context. Int. J. Geogr. Inf. Sci. 25, 
1011-1023. doi:10.1080/13658816.2011.558845

Van Niekerk, A., 2015. Stellenbosch University Digital Elevation Model ( SUDEM ) 2015 Edition. Stellenbosch.

Van Niekerk, A., 2010. A comparison of land unit delineation techniques for land evaluation in the Western Cape, South Africa. Land use policy 27, 937-945. doi:10.1016/j.landusepol.2009.12.007

Venter, F., Bristow, J., 1986. An account of the geopmorphology and drainage of the Kruger National Park. Keodoe. doi:10.4102/koedoe.v29i1.524 